\title{
EXISTE FALA NEUTRA PARA A POESIA?
}

(Is there neutral speech for poetry?)

\author{
Ana Cristina Fricke MATTE \\ (Universidade Federal de Minas Gerais)
}

RESUMO: Durante a investigação de parâmetros para controle de corpus de referência para estudos fonoestilísticos, observou-se que não se poderiam misturar dados de prosa e de poesia em função das diferenças estatisticamente significativas entre os dois. No caso da poesia, observou-se que a retirada das sentenças afetadas pelas impressões do locutor reduziu extremamente o corpus. Além disso, as outras sentenças mostraram-se muito próximas do padrão encontrado para a prosa. Dessas constatações surgiu a questão central do presente trabalho: o que seria uma fala de referencia para a poesia? A resposta além da análise dos dados, gravados por um informante com experiência na área e analisados acusticamente, envolve uma retomada dos pressupostos teóricos.

PALAVRAs-CHAVE: fonoestilística; emoção; modelamento prosódico; semiótica.

ABSTRACT: During the inquiry of parameters for control of corpus of reference for phonostylistic studies, it was observed that they could not mix data of prose and of poetry, both statistically different. For poetry, it was observed that cutting out from the corpus the affected sentences would reduce the corpus extremely. Moreover, the other sentences had revealed very next to the standard found for prose. Of these founds, the central question of the present work appeared: what would be the reference speech for the poetry? The reply beyond the analysis of the data, that was recorded from a speech analysis experienced informant and acoustically analyzed, involves one retaken of the estimated theoreticians.

KEY-WORDS: phonostylistic; emotion; prosodic modeling; semiotics.

\section{Introdução}

A expressão de emoções na fala é um tema recente que tem centralizado esforços de cientistas do campo das ciências da fala, no intuito de melhor compreender o processo para embasar uma síntese com resultados 
mais naturais e como uma das formas de diminuir o problema da variabilidade do sinal no campo do reconhecimento. Entrando na fonética acústica pela inusitada via da semiótica lingüística, nossa atuação consiste em buscar referências no conteúdo passional dos textos como responsável parcial pela variabilidade do sinal, por meio da comparação de um corpus de referência, presumivelmente neutro, com um corpus com emoção simulada, ambos corpora gravados pelo mesmo locutor.

Questionar a neutralidade da fala de referência foi a primeira etapa dessa pesquisa, o que foi feito pela realização de um experimento piloto, sucintamente relatado no tópico homônimo. $\mathrm{O}$ experimento resultou na elaboração do que chamamos de "teste de fala neutra", o qual foi aplicado ao corpus de referência da pesquisa propriamente dita. A aplicação deste teste, no entanto, conduziu à formulação de novos questionamentos, desta vez em relação à pertinência do conceito de neutralidade num corpus de poesia, dado que estivemos trabalhando desde o início com dois corpora, um de prosa e um de poesia como se cada tipo pudesse ter uma variante neutra e uma variante emotiva independentemente. Os resultados do teste estão apresentados no tópico correspondente.

O presente trabalho consistiu em observar os resultados do teste de fala neutra na poesia tanto no corpus de fala dita neutra quanto no de fala com emoção simulada, ou emotiva. Além deste resultado, apresentado no tópico 6, o tópico 5 apresenta resultados secundários da aplicação desta metodologia no corpus de fala emotiva em prosa.

Antes de relatar os experimentos citados, o próximo tópico procura descrever brevemente o quadro teórico fundador das hipóteses aqui investigadas, basicamente a hipótese segundo a qual a emoção na fala é irrupção corporal de uma paixão do sujeito sensível e, diferentemente da paixão que é contextual e encadeada no tempo, não passa de um desnível de tensão particular que sugere ao sujeito outro, o sujeito social, qual a possível paixão que está afetando o sujeito sensível, sujeito individual.

Todas as medidas foram obtidas com o auxílio do programa livre Praat (www.praat.org) e suas análises estatísticas foram realizadas com o programa Statistica, da Stat Soft. Inc. Com o programa Praat foram utilizados os scripts Beatextractor e Duracao, de autoria de Plinio Barbosa, além do SGDetector para MatLab, também de autoria de Plinio Barbosa e adaptado por esta autora para o Praat conforme a transcrição por ela utilizada. 


\section{Estética e ciência da fala}

Segundo a teoria semiótica de linha francesa na qual se baseiam os pressupostos aqui defendidos, emoção e paixão são fenômenos diferentes.

A paixão do medo, por exemplo, implica uma relação disfórica entre sujeitos ou entre sujeito e objeto, que a) pressupõe um conhecimento de um perigo real ou simulado e que b) permite prever, conforme o grau do medo e características próprias do sujeito, diferentes seqüências narrativas (fuga, paralisia, grito etc.). O medo é percebido por um observador qualquer somente se o corpo do sujeito com medo apresentar alterações em relação a seu comportamento considerado normal. Essa mudança de comportamento é, não só no medo como em outras paixões, involuntária: o sujeito é afetado pela paixão e esse afeto é a emoção (Greimas \& Fontanille 1993: 155).

Segundo essa perspectiva, portanto, a emoção é a expressão corporal da paixão e podemos concluir que falar em expressão da emoção na fala, como se costuma dizer na área, é uma impropriedade, cabendo falar, simplesmente, em emoção na fala, ou seja, alteração passionalmente motivada do plano da expressão da linguagem verbal sonora. A emoção seria um produto da alteração da tensão do sujeito, perceptível porque afeta o corpo do sujeito.

Observe que todo o conceito de emoção e paixão é perpassado pela oposição entre expressão e conteúdo, cara a Hjelmslev (Cf. 1968). A semiótica propõe três tipos de linguagens calcada na relação entre esses dois planos: sígnica, simbólica e semi-simbólica. A linguagem verbal é um exemplo de linguagem sígnica, pois nela a relação entre a expressão e o conteúdo é totalmente arbitrária. Um bom exemplo de linguagem simbólica são os emoticons, pois trata-se de uma relação motivada entre plano do conteúdo e plano da expressão; podemos citar exemplos menos icônicos, tais como a figura da pomba significando paz. Além disso, cabe notar que na linguagem sígnica não há relação necessária entre o número de elementos para expressar cada conteúdo, enquanto na linguagem simbólica a relação é de um para um. O terceiro tipo de linguagem conta com uma motivação parcial e a relação entre categorias de cada plano no lugar da relação entre elementos. Trata-se do sistema semi-simbólico, o qual não só é intermediário entre o sígnico e o simbólico como também pode ser pensado como um caminho para a simbolização, tratando-se, assim, de uma linguagem marcada pela instabilidade, e por esse motivo considerada por muitos semioticistas o grande caminho da arte moderna: 


\begin{abstract}
"Ernest Fischer, em Da necessidade da arte, cita um belo poema de Aragon que fala de uma moedinha que cai na calçada e tine. A moedinha que passa de mão em mão, sem cair, é uma moedinha da qual não se ouve mais a materialidade de que é feita; a que escapa das mãos e cai não apenas rompe a continuidade da circulação, mas tine, vibra, ressoa. Assim é a palavra na poesia moderna, que procura recuperar a voz da materialidade adormecida, sufocada sob a crosta sígnica da palavra em seu uso corrente" (Silva 1996: 10).
\end{abstract}

Portanto, a poesia declamada seria aquela cuja linguagem é dada por uma maximização do plano da expressão, de modo a recuperá-lo em ciclos tornando-o memorizável, enquanto a prosa coloquial pode ser considerada o estado da linguagem verbal no qual o plano da expressão deve ser volátil, não memorizável, a fim de maximizar seu conteúdo. Basta lembrar que dizer com minhas próprias palavras algo dito por outrem, ou seja, a mudança completa do plano da expressão é algo perfeitamente aceitável na prosa, sendo considerada uma forma de mostrar que o conteúdo foi apreendido. Por outro lado, dizer com minhas palavras o conteúdo de uma poesia seria descartar sua função estética, desvirtuar a poesia da qual estou tratando. Ou seja, saber a poesia é saber repetir, ipsis litteris, seu plano da expressão.

Em suma: a) emoção é expressão de paixão; b) a linguagem estética privilegia o plano da expressão, enquanto na linguagem utilitária o plano da expressão deve ser volátil, descartável. Principalmente a partir da segunda premissa cabe levantar, ao menos, duas hipóteses: (i) não se poderia esperar da locução de prosa e de poesia o mesmo padrão para a fala neutra e tampouco para a fala emotiva; (ii) provavelmente a locução de prosa emotiva é a mais variada e menos previsível, privilegiando ênfases locais descartáveis e não uma totalidade rítmico-melódica.

Embora a pesquisa descrita no presente artigo não tivesse o objetivo de testar essas hipóteses teóricas, os dados obtidos corroboram a perspectiva adotada pois sancionam tanto (i) quanto (ii), como se pode acompanhar nos tópicos seguintes.

\title{
3. O experimento piloto
}

O corpus do experimento piloto foi gravado por um locutor (PA), natural de Brasília, com experiência em estudos fonéticos e no conceito do que seria uma gravação de fala neutra para montagem de um corpus de referência. 
O locutor fez seis leituras de dois textos previamente desconhecidos, sendo um de prosa e um de poesia, ambos pertencentes ao corpus do locutor da pesquisa propriamente dita (CB). Após a gravação, solicitou-se ao locutor que relatasse suas impressões sobre aquelas sentenças que, por qualquer motivo, chamaram sua atenção durante a leitura.

A partir das medidas de unidades do tamanho da sílaba iniciadas no segundo pico da onda periódica de uma vogal até o segundo pico da onda periódica da vogal subseqüente (doravante unidade V-V ou, simplesmente, V-V), calculou-se o z-score de cada unidade com base em uma tabela de referência (Cf. Barbosa, 2004). A ANOVA de um fator para o z-score conforme a impressão relatada é altamente significativa mesmo se tomados os dois corpora simultaneamente, ou seja, prosa e poesia misturados $(\mathrm{p}=$ 0,0000). Em outras palavras, algumas impressões relatadas pelo locutor afetaram as sentenças alterando o z-score de suas unidades V-V.

Os relatos do locutor indicam as sentenças possivelmente afetadas por emoções ou outros fatores relatados, tais como a dificuldade de pronúncia.

Comparando-se os resultados de prosa com os de poesia, observou-se uma diferença significativa entre as médias de z-score e também do zsuavizado, que é uma suavização de 5 pontos dos dados de z-score e permite observar com mais precisão as proeminências de duração, ou seja, a periodicidade de ocorrência dos acentos frasais (Cf. Barbosa 2004). Tanto o z-score quanto o z-suavizado apresentam médias prosodicamente semelhantes para a prosa $(1,9)$ e para a poesia $(0,35)$, mas o teste pos-hoc Scheffé confirma a diferença significativa entre a prosa e a poesia tanto para o $\mathrm{z}$-suavizado quanto para o z-score (em ambos, $\mathrm{p}=0,00$ ).

Os resultados da análise dos relatos na prosa e na poesia serão retomados no decorrer do presente texto.

\section{O teste de fala neutra}

A função do teste de fala neutra é averiguar a existência de sentenças afetadas por emoções ou outras circunstâncias relatadas pelo locutor nas gravações de corpus de fala lida, em sessões com pretensões de neutralidade. $\mathrm{O}$ teste de fala neutra, elaborado a partir do experimento piloto, consiste em: a) solicitar relato de impressão do locutor sobre os trechos lidos 
após a gravação de amostras de fala para corpus de referência (preferencialmente textos previamente desconhecidos pelo locutor); b) realizar ANOVA de um fator (impressão relatada) para a variável dependente focalizada, no caso do presente trabalho o z-score e o z-suavizado; c) descartar do corpus de referência, se houver, todas as sentenças com diferença significativa das sentenças sem relato de impressão.

O teste parte da hipótese de que as sentenças sem relato de impressão seriam aquelas mais próximas do padrão "lingüístico", devendo ser usadas como referência. A partir dele é possível aproveitar as sentenças com relato que não apresentem diferenças significativas do comportamento geral das sentenças sem relato de impressão, incorporando-as ao corpus de referência.

Aplicou-se o teste às sessões de fala neutra gravadas pelo locutor CB, natural de Belo Horizonte e narrador profissional de histórias infantis.

A Figura 1 apresenta o resultado do teste de fala neutra para a prosa aplicado ao corpus gravado pelo locutor $\mathrm{CB}$ nas sessões de fala dita neutra. A linha pontilhada indica a média das sentenças "sem relato de impres-

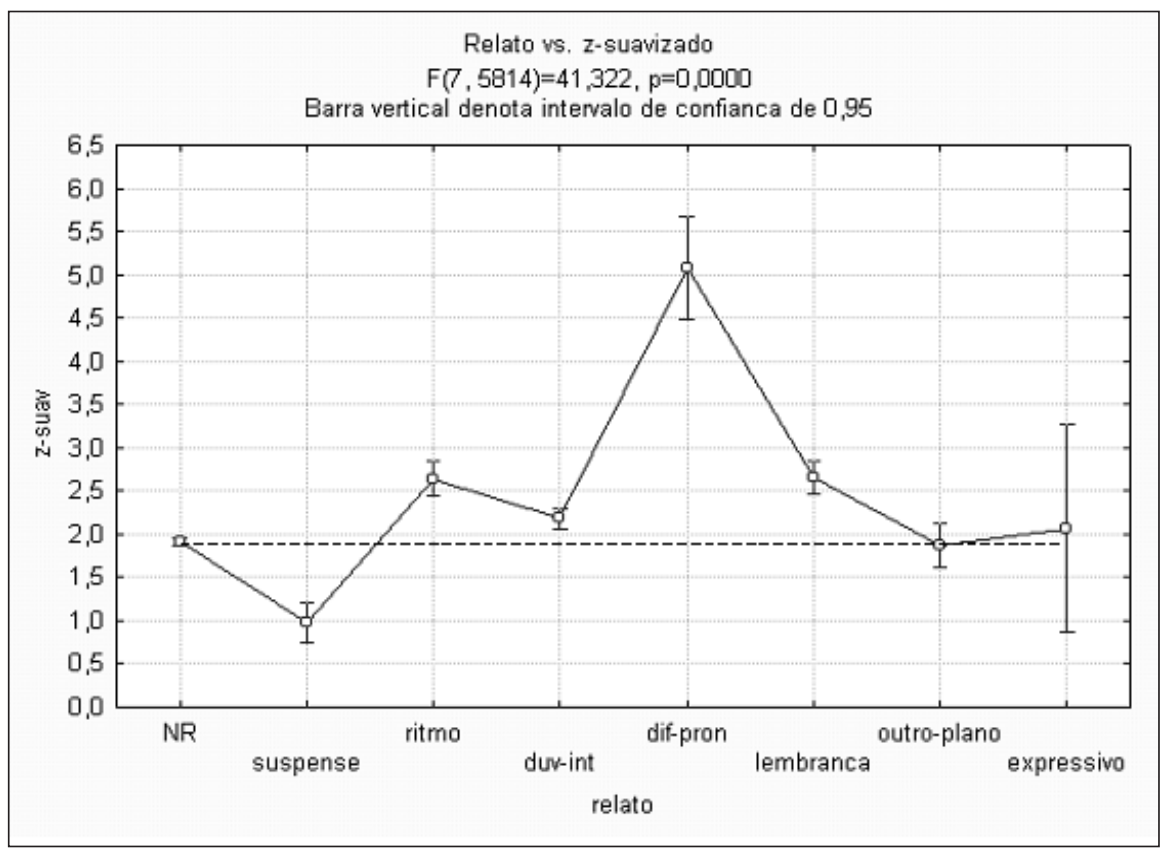

Figura 1: ANOVA de um fator (relato) para o z-score na prosa, durante o teste de fala neutra. 
são", que só não difere significativamente dos relatos de "evasão para outro plano ou dimensão" (outro-plano) e de "expressividade" (expressivo). Observe que a "dificuldade de pronúncia" (dif-pron) é o relato cujas sentenças mais se distanciam do padrão encontrado para a duração nas sentenças sem relato de impressão.

O resultado do teste de fala neutra para a poesia reduziu enormemente o corpus de referência. Conforme se pode observar na Figura 2, as poucas sentenças sem relato são significativamente diferentes de todas as sentenças com relato de impressão.

Esse resultado indicaria uma possível impropriedade do conceito de fala neutra para a poesia, pois considera-se, nos estudos desse campo do conhecimento, que a fala neutra seria definida por sua estabilidade, ou seja, variação mínima. No entanto, o resultado da pesquisa altera a idéia de tal impropriedade pois, como veremos, coloca poesia e prosa num mesmo eixo expressivo.

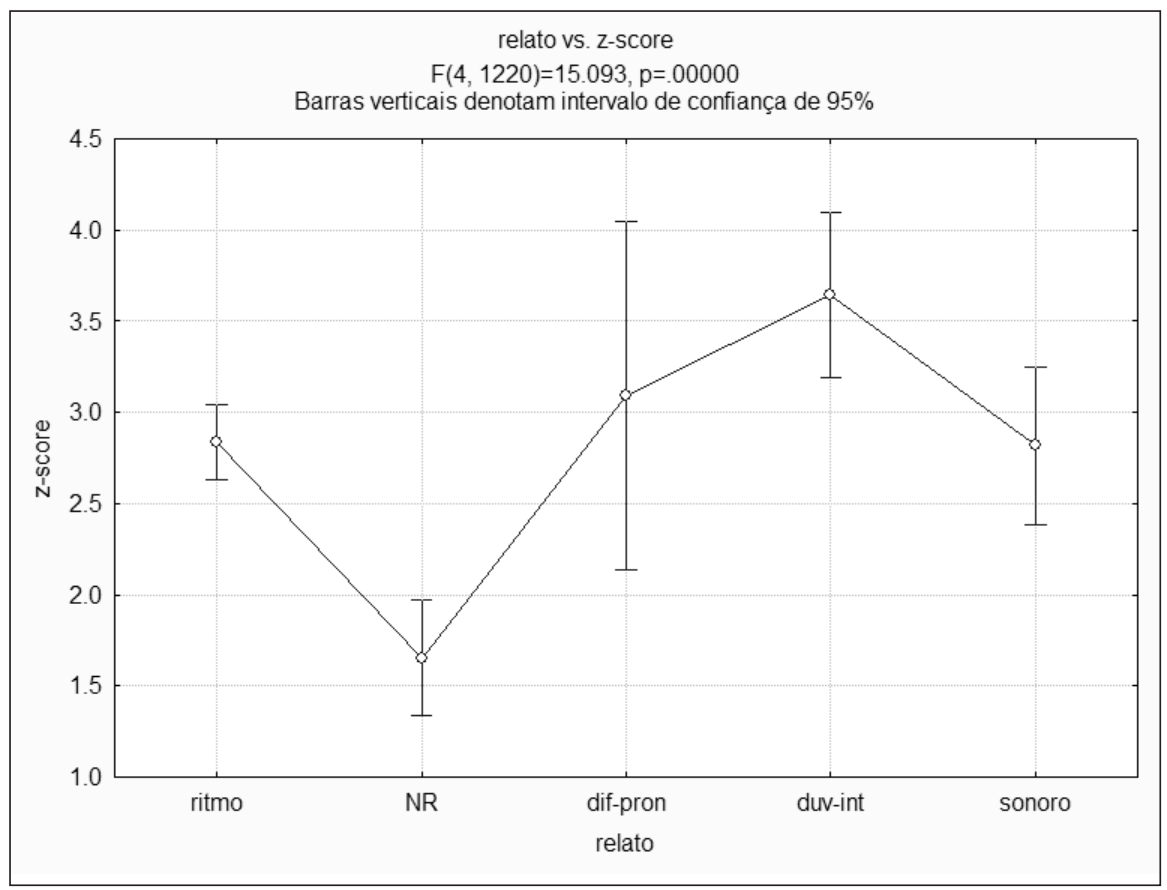

Figura 2: ANOVA de um fator (relato) para o z-score na poesia, durante o teste de fala neutra. 
O corpus de referência para a poesia, no caso do locutor $\mathrm{CB}$, deve, portanto, contar unicamente com os dados provenientes de sentenças sem relato de impressão.

\section{O teste de fala neutra na prosa: consequências no corpus de fala emotiva}

A fim de averiguar se as sentenças afetadas durante o teste de fala neutra também o foram durante a gravação de fala com emoção simulada, calculamos a taxa de elocução (TE) em unidades V-V por minuto nas frases do corpus de fala emotiva com os mesmos textos usados para o teste de fala neutra. Esperava-se que não haveria nenhum resultado significativo, dado que a duração, na leitura com emoção simulada, sofreria uma alteração conforme o que se poderia chamar de caricaturas vocais (Matte, 2004:1) desenhadas pelo locutor, um narrador profissional. O resultado desse teste revelou que um dos relatos continuava afetando a fala do locutor, o relato de dificuldade de pronúncia, como pode ser observado na Figura 3. Como se trata de dados de taxa de elocução, o gráfico apresenta-se invertido em relação aos dados de z-score observados na Figura 1 para a fala neutra.

Esse resultado é importante pois demonstra que, no caso desse locutor, a dificuldade de pronúncia inviabiliza as frases lidas mesmo após um período de estudo, que foi realizado com as leituras das sessões neutras e com o treino realizado antes das sessões com emoção simulada. Essas sentenças, portanto, devem ser retiradas tanto do corpus de fala neutra quanto do corpus de fala emotiva.

Além disso, dada a peculiaridade do relato em questão, o fato de que os outros tipos de relato não afetam a duração dos dados de fala emotiva reforçam a coerência tanto do corpus de referência quanto dos dados de fala emotiva, com comportamento diferente do primeiro.

O mesmo procedimento, dessa vez aplicado à poesia, deparou-se com um fator limitante: os versos sem relato de impressão foram, na fala emotiva, pronunciados sem separação prosódica de versos com relato, impedindo que se comparasse o efeito da presença/ausência de relato na fala emotiva, dado que a taxa de elocução foi medida em frases prosodicamente delimitadas. No entanto, foi possível observar que, enquanto no corpus de 


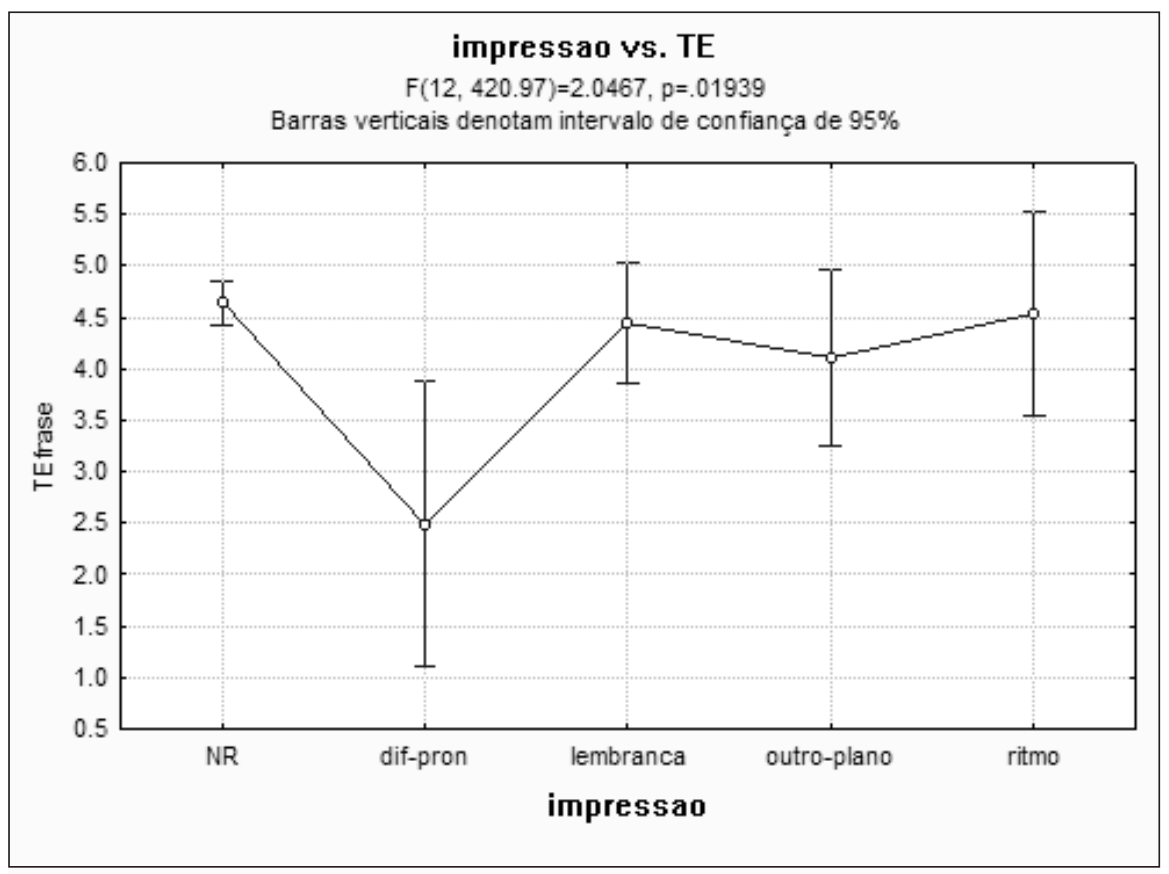

Figura 3: ANOVA de um fator (relato) para a taxa de elocução na prosa, no corpus de fala emotiva.

referência a sonoridade e o ritmo seguem um padrão semelhante (Figura 2), no corpus de fala emotiva eles se opõem, com o ritmo estatisticamente diferente do sonoro e bem mais lento do que este (Figura 4).

Esse resultado indica que o locutor tem um padrão diferenciado para aquilo que ele previamente determinou como "potencialidade rítmica" dos versos (ritmo) e "potencialidade sonora" dos mesmos (sonoro). Observa-se também na Figura 4 que a "dúvida na interpretação" (duv-int) permanece numa posição intermediária entre esses dois outros relatos na fala emotiva, não se distinguindo de nenhum deles. A menor taxa de elocução para a potencialidade rítmica possivelmente é um efeito da busca por um rítmo silábico. 


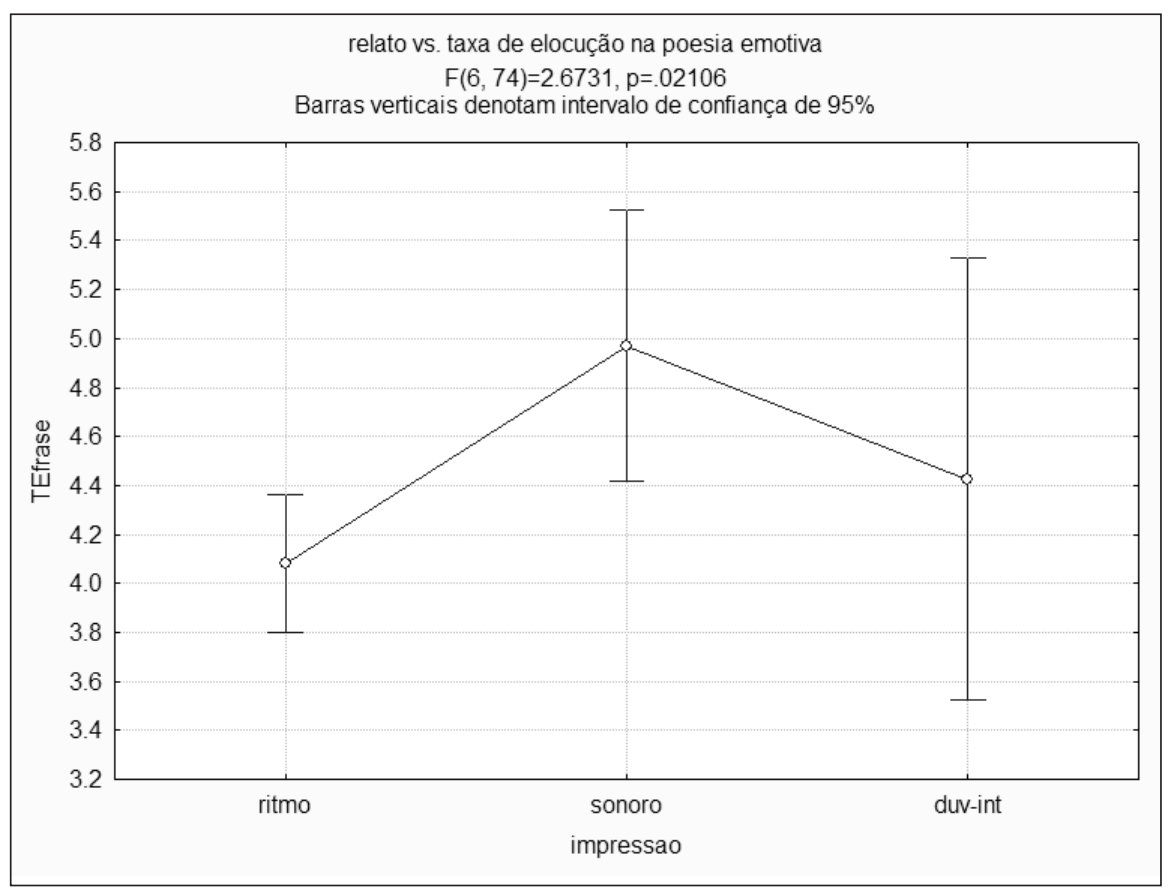

Figura 4: ANOVA de um fator (relato) para a taxa de elocução na poesia com emoção simulada.

\section{Comparando fala lida e fala com emoção simulada na poesia}

Como primeira semelhança entre a locução neutra de $\mathrm{PA}$ e de $\mathrm{CB}$, o teste de fala neutra com o corpus do locutor CB também apresenta diferenças significativas entre os dados de prosa e os dados de poesia $(\mathrm{F}(1,7051)=4,6107, \mathrm{p}=0,03181)$ para o z-score. Durante a pesquisa piloto com PA observou-se que o grupo acentual na poesia caracteriza-se por uma tendência ao "achatamento" das durações relativas, ou seja, apresenta uma menor diferença do que na prosa entre (i) as médias de z-suavizado da posição de acento frasal e a posição imediatamente anterior a ele e (ii) as outras posições no grupo. $\mathrm{O}$ teste de fala neutra em CB repete a tendência de "achatamento" do grupo acentual, no que diz respeito ao z-suavizado. 
A Figura 5 mostra diferenças significativas entre prosa e poesia na fala emotiva. A poesia, aqui como na fala neutra de $\mathrm{CB}$ e na fala neutra de $\mathrm{PA}$, apresenta-se com segmentos mais alongados do que a prosa.

As médias de z-score e z-suavizado na prosa são mais altas para o locutor $\mathrm{CB}$ do que foram para o locutor do experimento piloto, PA. Além disso, como se pode notar na Figura 6, não diferem significativamente da média de z-score dos dados de fala emotiva no mesmo locutor $\mathrm{CB}$, o mesmo ocorrendo para a poesia.

A variança dos dados de z-suavizado, ao se comparar prosa e poesia na fala neutra e na fala emotiva, apresenta o resultado mais relevante para o presente trabalho. Observe na Figura 7 como a poesia neutra apresenta a menor variança de todos os dados, enquanto a poesia emotiva e a prosa neutra apresentam varianças semelhantes e a prosa emotiva possui variança extremamente diferente das demais, muito mais alta.

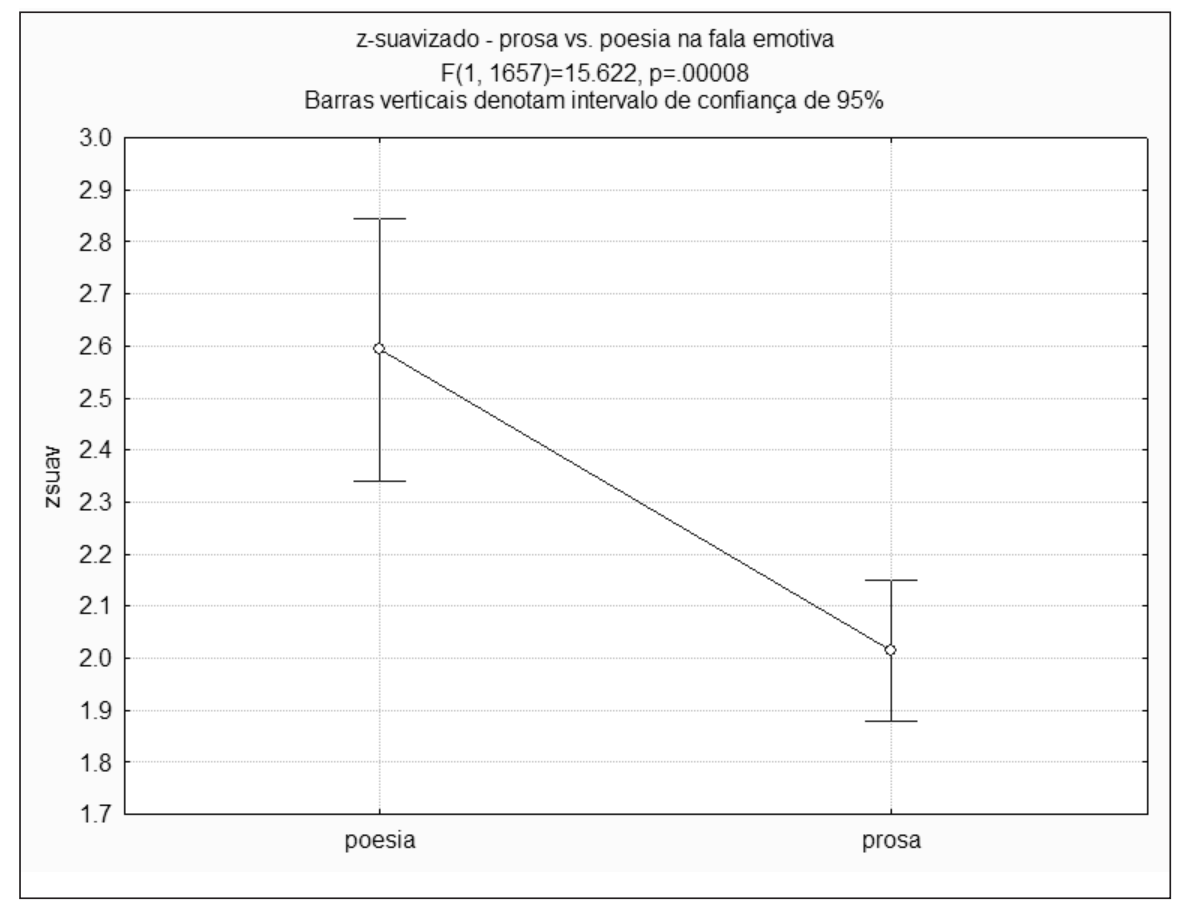

Figura 5: ANOVA de um fator (prosa/poesia) para

o z-suavizado com dados de fala emotiva. 


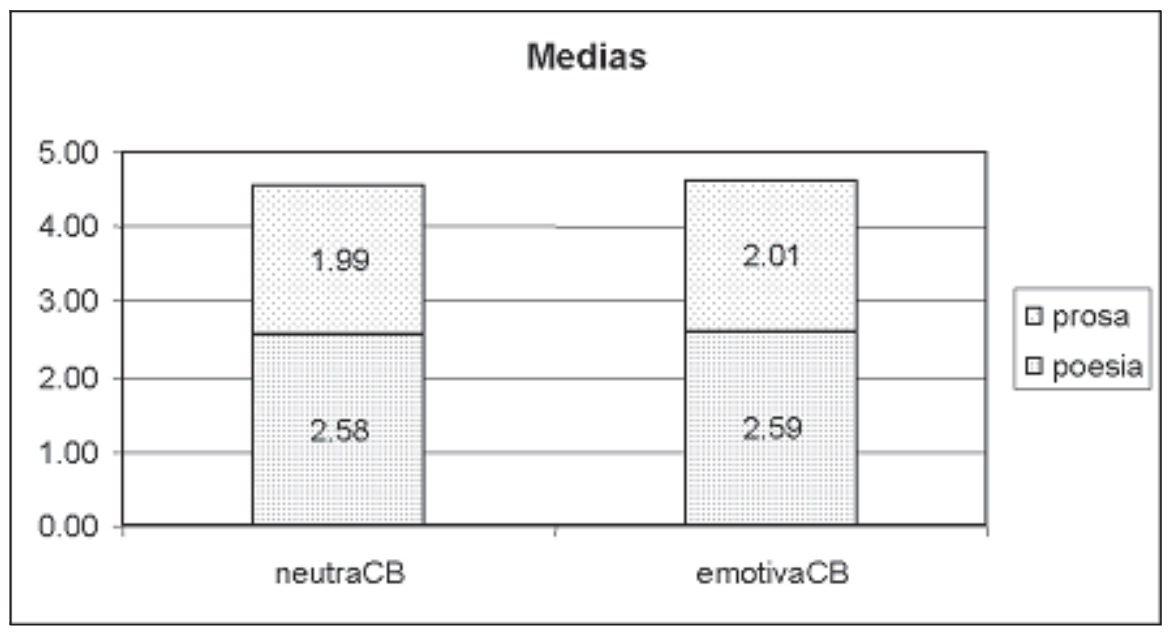

Figura 6: Médias de z-score em dados de fala nutra e de fala emotiva, com corpora de prosa e poesia.

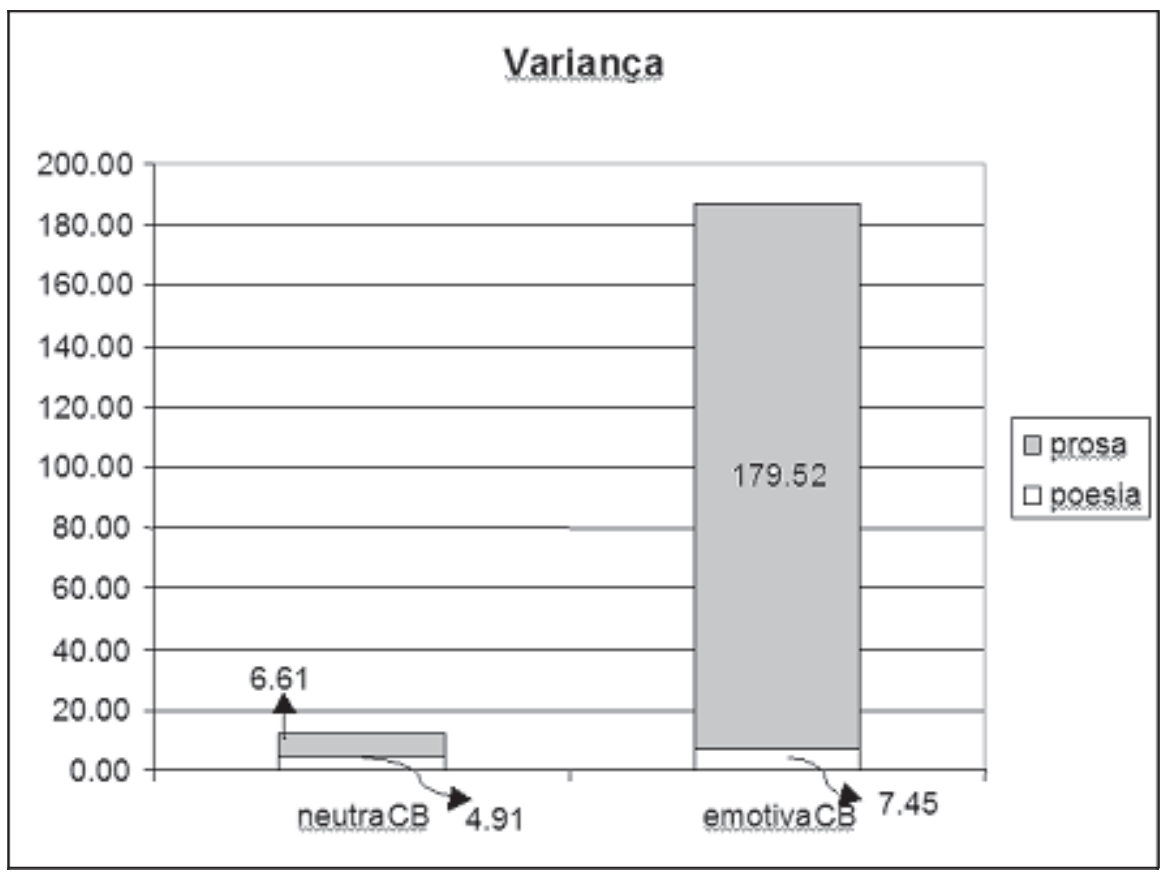

Figura 7: Variança dos dados de z-suavizado para prosa e poesia em corpora de fala neutra e de fala emotiva. 
Enquanto a poesia emotiva se aproxima da prosa neutra, a prosa emotiva difere de todas as outras, perdendo periodicidade na duração, fortalecendo as ênfases e, portanto, enfatizando as diferenças internas. Esse resultado é uma outra forma de apresentar a mesma informação obtida já no experimento piloto, em que a duração relativa na prosa apresenta um maior distanciamento da posição de acento frasal e sua antecendente da medida relativa das outras posições, no que concerne à duração. Ou seja, na prosa emotiva os acentos frasais ganham um destaque muito maior do que o recebido na prosa neutra ou na poesia, seja ela neutra ou emotiva.

A comparação do z-suavizado na poesia neutra com ou sem relato corrobora essa conclusão. A Figura 8a indica que o relato aproxima a poesia neutra da prosa, com diferenças significativas entre as posições frasalmente acentuada e imediatamente anterior e as outras posições, enquanto na poesia neutra sem relato a diferença é bem menor e não é estatisticamente significante, como se observa na Figura 8b. No entanto, a média dos dados de z-suavizado da poesia neutra sem relato são menores do que as dos dados de poesia neutra com relato e, nesse sentido, semelhantes às médias dos dados de z-suavizado para a prosa neutra.

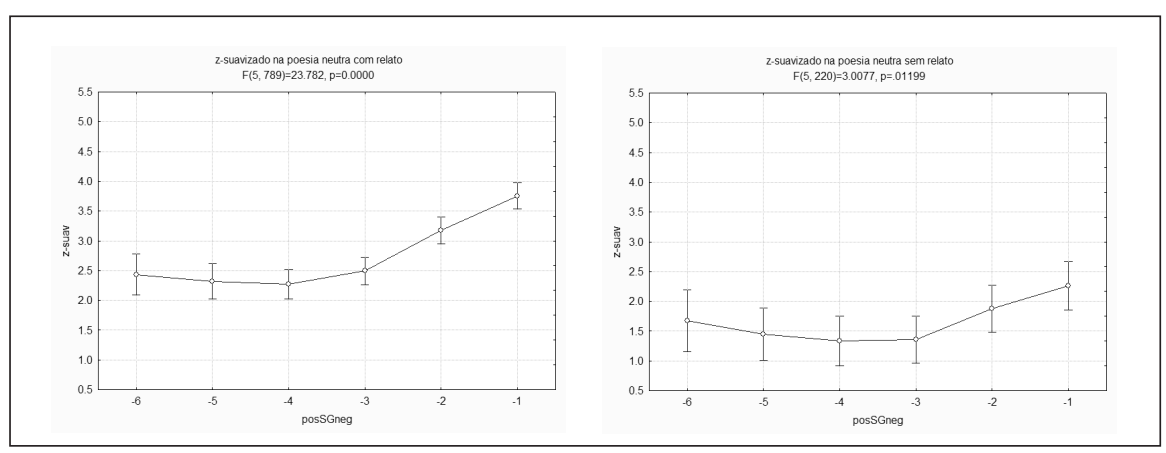

Figura 8a/b: A figura 8a (esquerda) é resultado de uma ANOVA de um fator (posição) para o z-suavizado na poesia com relato $(\mathrm{F}(5,789)=23.782$, $\mathrm{p}=0.0000$ ), enquanto $8 \mathrm{~b}$ (direita) resultou da mesma análise, desta vez focalizando dados de poesia sem relato $(\mathrm{F}(5,220)=3.0077, \mathrm{p}=.01199)$. 


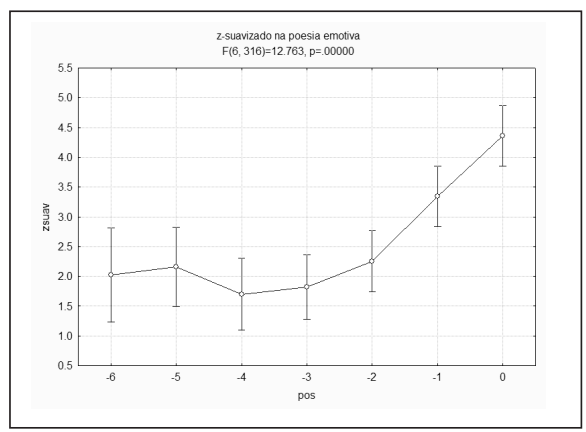

Figura 9: ANOVA de um fator para o z-suavizado conforme a posição no grupo acentual na poesia emotiva $(\mathrm{F}(6,316)=12,763, \mathrm{p}=0,00000)$.

Já a figura 9, com dados de poesia com emoção simulada, mostra que as posições átonas $(-6 \mathrm{a}-2)$ são semelhantes à média da poesia neutra sem relato, enquanto a posição de acento frasal tem destaque ainda maior do que aquele apresentado na poesia neutra com relato. A poesia neutra com relato (Figura 8a) sugere que o relato faz o conteúdo do verso ganhar importância, enquanto na poesia neutra sem relato prevalece o modelo escolar de declamação cadenciada de poesia, tendendo à silabicidade.

Além disso, nota-se que a seqüência de grupos acentuais é, na poesia neutra com relato, realizada com uma menor diminuição do z-score do que na poesia emotiva. Pode-se afirmar que a poesia neutra com relato suaviza os inícios dos grupos acentuais, com os alongamentos comportando-se como ondas, enquanto na poesia emotiva a queda é mais brusca e, portanto, perceptível, assemelhando-se à prosa neutra.

Os dados indicam uma gradiência que vai da poesia neutra sem relato, passa pela poesia neutra com relato e culmina na poesia emotiva, que seria a mais próxima da prosa neutra. Esse gradiente é um novo indício de que, da poesia neutra à prosa neutra, há um aumento na importância do conteúdo em detrimento da expressão.

\section{Conclusão}

Este trabalho, além de fortalecer a opção pelo uso do teste de fala neutra para aumentar a neutralidade de corpora de referência nos estudos 
em fonoestilística, indica que há, sim, uma fala neutra para a poesia, e que esta tem, dentre os corpora observados, o comportamento mais distante da prosa neutra.

A poesia emotiva, por sua vez, aproxima-se da prosa neutra, marcando as proeminências, ressaltando as ênfases e, assim, dando maior destaque ao conteúdo dos versos. O estudo até agora indica que haveria um gradiente entre estas modalidades de fala que vai da preferência pelo plano da expressão à preferência pelo plano do conteúdo (Figura 10).

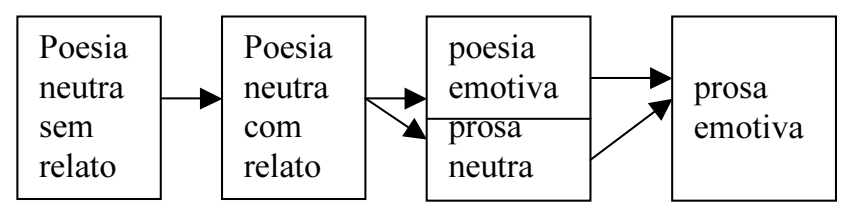

Figura 10: Do plano da expressão (poesia neutra sem relato) ao plano do conteúdo (prosa emotiva).

Esses resultados reforçam, além disso, a opção teórica para a análise do conteúdo, dado que as hipóteses que a teoria de texto aqui utilizada sugere são ambas sancionadas por eles. Mais especificamente, os resultados reafirmam a hipótese inicial da pesquisa maior na qual se insere este trabalho: as pistas sobre a expressão de emoções na fala estão, provavelmente, no conteúdo dos textos lidos.

Digna de nota é a validação da sugestão da teoria semiótica de pertinência, para o trabalho em fonoestilística, do uso de textos completos como corpo$\mathrm{ra}$, provendo maior controle do contexto no qual cada sentença se insere.

Recebido em março de 2005 Aprovado em agosto de 2007 E-mail: a9fm@yahoo.com

\section{REFERÊNCIAS BibliográFiCAS}

Barbosa, P. A. 2004. Elementos para uma tipologia do ritmo (lingüístico) da fala à luz de um modelo de osciladores acoplados. In Cognito Cadernos Românicos em Ciências Cognitivas. v. 2 n. 1, no prelo. 
Greimas, A. J. \& Fontanille, J. 1993. Semiótica das Paixões - dos estados de coisas aos estados de alma./trad. Maria José Rodrigues Coracini. Série Temas 33. São Paulo: Ed. Ática.

Hjelmslev, L. 1968. Prolégomènes a une théorie du langage et-la structure fondamentale du langage. Traductin Anne-Marie Léonard. Paris: Les Editions De Minuit (Série Arguments 35).

Matte, A. C. F. 2004. Relating Emotional Content to Speech Rate in Brazilian Portuguese In: Speech Prosody 2004 CD: Nara, Japan.

SiLva, I. A. 1996. A Escuta do Sensível. In: Silva, Ignacio Assis. Org. Corpo e Sentido: a escuta do sensível. São Paulo: Editora da Universidade Estadual Paulista. 